\title{
TRIBUTAÇÃO E LIVRE INICIATIVA SOB O VIÉS DA AUSÊNCIA DE DOSIMETRIA NAS MULTAS FISCAIS DE ICMS E SEUS REFLEXOS NO DESENVOLVIMENTO
}

\author{
TAXATION AND FREE INITIATIVE UNDER BIAS DOSIMETRY LACK OF \\ FINES IN TAX ICMS AND ITS CONSEQUENCES IN DEVELOPMENT
}

${ }^{1}$ Simone Cruz Nobre

\begin{abstract}
RESUMO
A arrecadação do ICMS é a principal fonte de recursos que dispõe o Estado para a garantia e satisfação dos direitos fundamentais. No entanto, a complexidade em sua tributação, a excessiva quantidade de obrigações acessórias e a ausência de uma graduação ou limite do poder sancionador estatal são fatores decisivos que impactam não apenas na concorrência, mas na atração de novos investimentos. Portanto, é fundamental a compreensão desta problemática, a fim de que seja possível o exercício do poder sancionador tributário dentro da moldura constitucional, que prima pelo desenvolvimento nacional, a liberdade e a solidariedade.
\end{abstract}

Palavras-chave: Multas fiscais, Desenvolvimento, Livre iniciativa

\begin{abstract}
The collection of ICMS is the main source of funds available to the State to guarantee and satisfaction of fundamental rights. However, the complexity of its taxation, excessive amount of ancillary obligations and the absence of a degree or limit the state sanctioning power are key factors that impact not only on competition, but in attracting new investments. Therefore, understanding this issue is critical, so that you can exercise the tax sanctioning power within the constitutional framework, to press for national development, freedom and solidarity.
\end{abstract}

Keywords: Tax-related fines, Development, Free enterprise

\footnotetext{
${ }^{1}$ Mestre em Direito Políticas Públicas e Direitos Humanos pelo Centro Universitário do Estado do Pará, CESUPA - PA , (Brasil). Pós-graduada em Direito Tributário pela Fundação Getúlio Vargas, FGV - SP, (Brasil). E-mail : sequecruz@yahoo.com.br
} 


\section{INTRODUÇÃO}

O Estado tem uma difícil e árdua função de conciliar escassez de recursos com a promoção dos direitos elencados no texto constitucional, sendo a tributação o principal meio que dispõe para obter os recursos necessários à garantia e satisfação desses direitos.

O Estado deve lidar, porém,com a intrínseca dificuldade do homem em respeitar o ordenamento jurídico, principalmente, no que se refere às normas tributárias, que não apenas reduzem a sua disposição financeira para viver uma vida boa, como lhe impõem obrigações nem sempre tão simples de cumprir.

Diante disso, o Estado é dotado de competência para instituir as sanções, a serem utilizadas como meio de coagir os cidadãos ao cumprimento das obrigações tributárias. É o próprio texto constitucional, fundado no respeito ao princípio da igualdade e da legalidade que legitima esta conduta.

No entanto, se, por um lado, a competência do Estado não se limita ao poder de instituir, normatizar, arrecadar, fiscalizar os tributos, mas, também, de impor sanções por seu inadimplemento; por outro, este poder deve ser equacionado com os direitos e princípios protegidos em nossa Carta Magna.

Desta forma, assim como o poder de tributar, o poder de impor sanções em matéria tributária se vê afeto ao ius tributandi, devendo respeitar os princípios intrínsecos ao Direito Tributário.

Necessário, ainda, que tal poder estatal seja exercido em consonância com os demais princípios insertos no ordenamento constitucional, inclusive aqueles que estruturam a ordem econômica e social do país.

Neste sentido, as sanções devem atender a necessidade de eficácia do poder punitivo estatal, sem, contudo, chegar à desmedida de inibir a própria atividade econômica.

Na prática, porém, observa-se com frequência a ausência de critérios claros para a fixação das sanções fiscais e o desrespeito aos princípios constitucionais que as conformam.

É dentro dessa problemática que se desenvolverá o presente ensaio, analisando a necessidade de compatibilização do poder punitivo estatal em matéria tributária e os princípios que informam a configuração do desenvolvimento econômico e social do país, tendo como pano de fundo o ICMS. 
Em um primeiro momento, tratar-se-á da importante função da tributação para a concretude dos direitos fundamentais no Estado Democrático de Direito.

Em seguida, será ressaltada a interligação entre a tributação e a ordem econômica e social, por meio do princípio da livre iniciativa.

No terceiro capítulo, buscar-se-á identificar algumas das principais dificuldades enfrentadas pelo setor produtivo para cumprimento das obrigações tributárias, especialmente no que tange ao ICMS.

No quarto capítulo será abordado o reflexo que a ausência de dosimetria nas multas fiscais impõe ao desenvolvimento econômico e social do país.

\section{O PAPEL DA TRIBUTAÇÃO NO ESTADO SOCIAL E DEMOCRÁTICO DE DIREITO.}

A tributação e o dever de pagar tributos constituem manifestações importantes da sujeição dos indivíduos face ao Estado (ESCRIBANO, 1998, p.53). E embora essa sujeição seja legítima em si, ela não implica uma submissão incondicional dos indivíduos ao poder estatal.

Em um Estado Democrático de Direito, os tributos não são cobrados para responder a necessidades de um Estado que existe fora da sociedade. Eles são criados para satisfazer às exigências da sociedade, concretizadas pelo respeito de um nível mínimo de dignidade para todos os indivíduos que a compõem (DELGADO, 2004, p.156).

Conforme explica A. Steichen (2002, p.266) "o sistema fiscal faz parte de um sistema político em que aparece como o instrumento que permite trazer respostas às demandas formuladas pela sociedade como um todo".

O mesmo raciocínio guia o pensamento de F. Escribano (1998, p.53), o qual explica que a relação de subordinação produzida pelo poder de tributar sobre os contribuintes implica que todos os cidadãos possam desfrutar das benesses produzidas pela atividade do Estado.

Já para Juan Barquero Estevan (2002, p.35), alimentado pelas ideias de Schumpeter, o Estado encontra limites a seu poder de tributar justamente porque ele deve retirar da economia privada somente aquilo que seja compatível com a existência contínua do 
interesse dos contribuintes, já que são eles que representam a força propulsiva da economia privada que sustenta, em última instância, o próprio Estado.

O tributo, então, ao mesmo tempo em que parece violar direitos fundamentais garantidos aos indivíduos - imiscuindo-se no direito de propriedade e na própria liberdade dos cidadãos - serve ao financiamento das ações do Estado para a manutenção do sistema jurídico e das prestações sociais, que garantem a existência desses direitos fundamentais.

O poder de tributar não configura, portanto, um poder arbitrário nem discricionário. Trata-se, como todo poder estatal, de uma faculdade regida e limitada pela ordem jurídica (TRAIBEL, 1990, p.21). As normas que enquadram o poder de tributar se encontram, essencialmente, inscritas na Constituição, a qual, na concepção moderna de Estado, consagra os valores da sociedade e dirige a ação dos poderes públicos.

Considerando, pois, que o poder público utiliza os instrumentos fiscais para atingir objetivos predeterminados, esses objetivos devem estar fundados em valores sociais, políticos e econômicos, de forma completamente atrelada às normas inscritas na Constituição, principalmente àquelas definidoras de direitos fundamentais ${ }^{1}$.

Em contrapartida, o poder de tributar não se legitima se os fins perseguidos pelo Estado não corresponderem aos valores sociais e às finalidades estatais estipuladas pela Constituição ${ }^{2}$.

Por certo, a Constituição impõe restrições formais ao poder de tributar, compostas pelas regras que estabelecem as diretrizes para a instituição e cobrança dos tributos, as quais configuram as conhecidas limitações constitucionais relativas ao sistema tributário nacional.

\footnotetext{
${ }^{1}$ Veja a respeito BARCELLOS, A eficácia jurídica dos princípios constitucionais: o princípio da dignidade da pessoa humana, p. 240241.

2 Nesse sentido, Roberto Ferraz comenta a insuficiência da aprovação formal da lei instituidora de um tributo. Às vezes a destinação do produto da arrecadação fiscal pode ser essencial para a verificação da

legitimidade da cobrança. Cf. FERRAZ, R., "A inconstitucionalidade dinâmica da Cide-combustíveis", p. 452 .
} 
No entanto, não existem apenas limitações formais ao poder de tributar. A necessidade de compatibilização do sistema tributário com os direitos fundamentais e demais princípios inscritos na Constituição indica que a concepção formal de Estado de Direito é complementada por uma concepção material ${ }^{3}$.

Isso quer dizer que a cobrança dos tributos deve respeitar a liberdade formal dos contribuintes, mas deve também fundar as ações positivas do Estado para a implementação material dos princípios constitucionais, de uma liberdade substancial ligada à promoção de melhores condições de vida aos cidadãos.

Nesse sentido, Monteiro Traibel (1990, p.23) afirma que a tributação sofre, além dos limites jurídicos, econômicos e políticos, outros limites ligados ao livre e pleno exercício dos direitos humanos, os quais são representados pela implementação de condições de igualdade materiais entre os indivíduos. A legitimidade do tributo deve, então, estar ligada à realização dos objetivos do Estado social dentro de um contexto de livre iniciativa.

Desta forma, fica claro, repita-se, que o poder de tributar é limitado não apenas por um conteúdo formal, mas também pelos critérios materiais, substanciais e teleológicos. Trata-se, tecnicamente, de um alargamento do campo da justiça fiscal para o campo da justiça financeira (TORRES, 2005-A, p.26), mas, na prática, a articulação de todas essas medidas é o que legitima o poder de tributar como um todo.

A legitimação do poder de tributar depende, portanto, da elaboração de políticas estatais e da utilização das receitas tributárias considerando-se de modo harmônico e sistemático os princípios fundamentais consagrados constitucionalmente.

Diante disso, os tributos ultrapassam a função de mera fonte de manutenção estatal, passando a ser entendidos como principal mecanismo de combate das desigualdades sociais e distribuição de rendas. A solidariedade passa a ser o fundamento para o dever de contribuir com o desenvolvimento social.

\footnotetext{
${ }^{3}$ Como afirma German Bidart Campos « la actividad financiera pública es así una actividad constitucionalmente juridicizada de naturaleza instrumental, pero no sólo en sentido formal (en cuanto la constitución determina las competencias de los órganos habilitados para ejercerla) sino sobre todo en sentido material (en cuanto se ancla en la constitución para fines determinados, de acuerdo a principios y valores) ». BIDART CAMPOS, G. J., El orden socioeconómico en la Constitución, p. 363.
} 
No atual Estado Social e Democrático de Direito constitucionalmente definido, a tributação se vê, ainda, como elemento chave destinado a equacionar o sistema econômico de mercado com a implementação dos direitos sociais (CARDOSO, 2014, P.139).

A tributação é, pois, o instrumento de regulação e ação econômica que permite a manutenção da livre iniciativa, como ensina Hugo de Brito Machado (2007, p.56):

\footnotetext{
A tributação é, sem sombra de dúvida, o instrumento de que se tem valido a economia capitalista para sobreviver. Sem ele não poderia o Estado realizar os seus fins sociais, a não ser que monopolizasse toda a atividade econômica. $\mathrm{O}$ tributo é inegavelmente a grande e talvez única arma contra a estatização da economia.
}

Assim, a partir do momento que passamos a compreender a importância da arrecadação para o cumprimento dos direitos fundamentais, passamos a entender que a tributação não pode ser interpretada como um sacrifício obrigatório que extrai do ser humano parte de sua riqueza, despida de fundamentos transcendentes.

A tributação possui seu fundamento na própria solidariedade, na cooperação entre os indivíduos que fazem parte de uma sociedade, com fulcro em um objetivo ainda maior: restabelecer a igualdade efetivando a plena liberdade.

Assim, o tributo deve ser interpretado não apenas como o "preço da liberdade" (TORRES, 2005-B, p.04), mas ao mesmo tempo, a medida de correção das desigualdades.

\section{A TRIBUTAÇÃO FACE À LIVRE INICIATIVA}

Quando se fala que a Constituição Federal de 1988 está assente sob a forma de Estado Social e Democrático de Direito, devemos entender a tributação não apenas como necessária para manutenção dos gastos públicos, mas, também, como um dever de solidariedade do indivíduo para com a sociedade. O dever de recolher tributos é, assim, fruto do exercício de sua cidadania. 
Neste sentido, a falta de recolhimento dos tributos deve ser lida não apenas com um descumprimento de um dever legal, mas um rompimento do seu vínculo de responsabilidade social.

Convém ressaltar que o art. $1^{\circ}$ da Constituição Federal de 1988, ao definir o Brasil como Estado Democrático de Direito, traz a necessidade de serem conjugados a cidadania, o pluralismo político, a dignidade da pessoa humana, os valores sociais do trabalho e a livre iniciativa.

A partir desta conjugação de elementos, a Constituição fundada na democracia e com seu núcleo fincado na dignidade da pessoa humana, elenca dentre os seus objetivos fundamentais, a construção de uma sociedade livre, justa e solidária, bem como, a redução das desigualdades sociais e regionais visando ao desenvolvimento nacional.

Dentro deste escopo, o Estado precisa, além de garantir o respeito aos direitos fundamentais, garantir o atendimento das necessidades básicas da população, proporcionar um sistema de saúde eficiente, uma educação de qualidade, saneamento básico e infraestrutura capaz de propiciar crescimento e aquecimento da economia, conciliando, assim, não apenas um papel de gestor, de arrecadador, mas, também, de articulador dos direitos e deveres sociais.

A fim de que possam cumprir com as atribuições que lhe são conferidas e arcar com as despesas originadas dessa valorosa missão, a Constituição Federal confere competência aos entes federativos para instituírem tributos, garantindo-lhes meios necessários para assegurar os direitos fundamentais e sociais para a promoção de uma vida social digna.

A tributação, portanto, tem um papel fundamental neste cenário, uma vez que grande parte dos recursos públicos disponíveis no orçamento do ente federado advém de receitas públicas derivadas, extraídas do exercício do seu poder coercitivo.

Este entendimento ganha dimensão frente à adoção pela Constituição do modelo de Estado, no qual a tributação é vista como o principal meio para obtenção de receitas, uma vez que prevê a atuação do Estado como agente econômico apenas em caráter excepcional.

Contudo, como se viu, a legitimidade da tributação implica em respeito aos limites formais e materiais do Estado Democrático de Direito. Comumente, porém, se analisa a relação entre a tributação e os direitos fundamentais enfatizando a garantia da 
liberdade e propriedade dos indivíduos. Pouca relevância recebe, porém, a relação da tributação com a ordem econômica e social constitucionalmente assegurada.

Diante disso, faz-se imperioso ressaltar que entre os fundamentos do Estado Democrático de Direito está a livre iniciativa, base essencial para proteção de uma Constituição que tem como vetor a proteção da dignidade da pessoa humana.

Por outro lado, não deve o legislador esquecer, também, que o direito de propriedade é um direito fundamental, protegido no texto constitucional, tanto no art. $5^{\circ}, \mathrm{XXII}^{4}$, como no art. 170 da Constituição Federal de 1988, o qual o insere como princípio da ordem econômica ${ }^{5}$.

Ademais, o Sistema Tributário guarda a mesma diretriz quando veda a instituição de tributo com efeito de confisco ${ }^{6}$.

Portanto, é nítida a necessidade de a tributação observar, em seu balizamento, além da sua função, o direito à livre iniciativa e o direito de propriedade.

Assim, no momento em que a Constituição Federal de 1988, visando à proteção da dignidade da pessoa humana, elenca que um dos objetivos fundamentais do Estado será garantir o desenvolvimento nacional, a ordem econômica deverá ser interpretada dentro desta mesma diretriz.

Com efeito, na leitura do art. 173 da Constituição Federal, podemos constatar que a nossa Carta Magna direcionou à iniciativa privada a titularidade das atividades econômicas, deixando ao Estado atuar apenas nas situações excepcionais ${ }^{7}$.

O fato é que a opção de afastar-se do exercício da atividade econômica demonstra a sintonia do Estado com a preocupação de garantir a efetividade de direitos

\footnotetext{
${ }^{4}$ BRASIL. Constituição (1988). Constituição da República Federativa do Brasil: promulgada em 5 de outubro. 14. Ed. Vade Mecum. São Paulo: Saraiva, 2012. "Art. 5\%. Todos são iguais perante a lei, sem distinção de qualquer natureza, garantindo-se aos brasileiros e aos estrangeiros residentes no país a inviolabilidade do direito à vida, à liberdade, à igualdade, à segurança e à propriedade, nos termos seguintes: (...) XXII- é garantido o direito de propriedade;(...)"

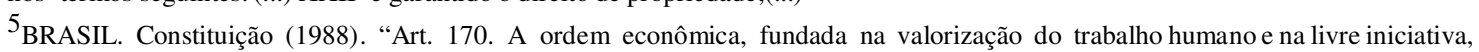
tem por fim assegurar a todos existência digna, conforme os ditames da justiça social, observados os seguintes princípios:I - soberania nacional;II - propriedade privada;III - função social da propriedade;IV - livre concorrência; (...)"

${ }^{6}$ BRASIL. Constituição (1988). Art. 150. Sem prejuízo de outras garantias asseguradas ao contribuinte, é vedado à União, aos Estados, ao Distrito Federal e aos Municípios:I - exigir ou aumentar tributo sem lei que o estabeleça; (...); V - utilizar tributo com efeito de confisco; (...)

7 BRASIL. Constituição (1988). “Art. 173Ressalvados os casos previstos nesta Constituição, a exploração direta de atividade econômica pelo Estado só será permitida quando necessária aos imperativos da segurança nacional ou a relevante interesse coletivo, conforme definidos em lei”.
} 
fundamentais como a dignidade da pessoa humana, igualdade, liberdade, deixando que a própria sociedade determine o que produzir, o que consumir.

Neste sentido, a definição de uma tributação específica para um determinado segmento ou produto, bem como a intensidade na multa tributária, embora seja uma decisão política, não deixa de ser uma intervenção do Estado no gosto e na preferência de sua população, que influencia diretamente em seu consumo, na escolha do segmento da atividade econômica a desenvolver.

Neste sentido afirma Sen (2000, p.71):

Os fins e os meios do desenvolvimento exigem que a perspectiva da liberdade
seja colocada no centro do palco. Nessa perspectiva, as pessoas têm que ser
vistas como ativamente envolvidas - dada à oportunidade - na conformação de
seu próprio destino, e não apenas como beneficiárias passivas dos frutos de
engenhosos programas de desenvolvimento.

Assim, o papel do Estado como legislador será disciplinar a relação entre Estado e iniciativa privada, de forma que o ordenamento jurídico seja um instrumento de atração de investimentos. Desta forma, a legislação tributária, se disciplinada com essa percepção poderá garantir um sistema de mercado satisfatório.

Este entendimento conduz Gilberto Bercovici (2010, p.13) a afirmar que: "O grande desafio da superação do subdesenvolvimento é a transformação das estruturas socioeconômicas e institucionais para satisfazer as necessidades da sociedade nacional”.

O fato é que, se a Administração Pública não tiver a visão da atividade econômica como parceira na construção de um Estado forte, uma sociedade livre, justa e solidária estará muito longe de ser efetivada.

\section{O ICMS NO CONTEXTO TRIBUTÁRIO ATUAL}

Muito embora o texto constitucional assevere que o Brasil constitui-se em um Estado Democrático de Direito, devido às suas dimensões e às diferenças regionais dos entes federados, os recursos públicos obtidos nem sempre conseguem suprir as despesas correntes para fazer frente à garantia dos direitos constantes na Carta Magna. 
Os números mostram que o governo federal é responsável por $69,96 \%$ de toda a arrecadação tributária nacional. Os Estados participam com 24, 71\% desta arrecadação, ficando os Municípios com 5,33\%, segundo o Instituto Brasileiro de Planejamento Tributário - IBPT (IBPT, 2012, p.05).

Sem grande esforço é possível verificar um latente desequilíbrio na arrecadação tributária nacional.

Importante destacar que o imposto de maior arrecadação nacional é o ICMS. Em 2010, o ICMS representava 21,09\% da receita tributária, seguida pelo IR com 17,53\%. Sendo que, aproximadamente, $47 \%$ de toda tributação recai sobre bens e serviços (RECEITA FEDERAL, 2011, p.13).

Se, por um lado, o ICMS representa a mais importante fonte de receita que dispõe o Estado para o financiamento de suas políticas públicas necessárias à promoção do desenvolvimento social, este imposto também carrega não apenas uma regressividade elevada, afetando principalmente a camada menos favorecida da população, mas onera a produção, afetando a competitividade das empresas da região.

O fato é que o ICMS, por ser um imposto presente nas operações comerciais, inclusive nas operações com energia elétrica, combustíveis e seus derivados, bem como nos serviços onerosos de comunicação e transporte interestadual, incide em praticamente toda a cadeia produtiva, reduzindo as disponibilidades financeiras das empresas, desestimulando investimentos e, muitas vezes, vindo a afetar, também, a própria eficiência dos meios de produção.

Assim, se hoje a globalização e a tecnologia chegam para facilitar e expandir o volume de negócios e transações econômicas, simplificando e reduzindo custos, a tributação do ICMS permanece envolta em uma densa legislação, onde vários fatores contribuem para o insucesso de inúmeras atividades comerciais.

Primeiro, muito embora o fato gerador do ICMS, em regra, ocorra na saída da mercadoria do estabelecimento do contribuinte, com transmissão de propriedade, muitos produtos possuem regime de tributação sujeito à substituição tributária ou com pagamento antecipado na entrada do território do Estado. Este fato acarreta um desembolso financeiro, muitas vezes, retirando da atividade econômica recursos necessários a investimentos ou projetos de expansão da sua atividade mercantil. 
Não se deve esquecer que o desembolso do imposto se dá de forma integral, mesmo que as operações comerciais se realizem de forma parcelada.

Segundo, a autonomia de cada Estado para regulamentar este imposto, propicia uma alta complexidade da legislação do ICMS, dificultando transações, uma vez que em operações interestaduais com substituição tributária, nos termos da Cláusula oitava do Convênio ICMS no $81 / 93^{8}$, deverá ser obedecida a legislação do Estado de destino das mercadorias.

Terceiro, a excessiva quantidade de obrigações acessórias a que estão sujeitas as empresas, onerando consideravelmente os custos com equipamentos, sistemas e equipes de profissionais destinados exclusivamente para esses controles contábeis, além das despesas com consultas tributárias especializadas.

Quarto, a ausência de previsibilidade na conduta administrativa tributária e nos critérios utilizados na dosimetria das multas fiscais, impondo custos à atividade empresarial com inúmeras demandas administrativas e judiciais onde nem sempre se consegue prever o seu desfecho.

Este último fator, muitas vezes já entrelaçado com a excessiva quantidade de obrigações acessórias, merece uma atenção destacada, pois repercute de forma incisiva sobre a economia, afetando, inclusive investimentos externos, uma vez que não oferece confiabilidade e segurança para o desenvolvimento da atividade empresarial.

Com efeito, uma mera ação judicial, sem definição de como será interpretada pelos tribunais, já provoca dano a instituição. Logo, a depender do tipo de sociedade, o dano pode ser muito maior do que a autuação ${ }^{9}$.

Importante destacar que, hodiernamente, quanto maior a segurança jurídica, a previsibilidade nos resultados do investimento, sem surpresa nas lides administrativas e judiciais na seara fiscal, maior será a inclinação das empresas para investir.

\footnotetext{
8“Cláusula oitava $\mathrm{O}$ sujeito passivo por substituição observará as normas da legislação da unidade da Federação de destino da mercadoria”, da Lei Complementar n 81, de 10 de setembro de 1993.

${ }^{9}$ A título de exemplificação, recentemente, autuações realizadas pelo Fisco Federal no Banco Itaú, na monta de R\$ 18, 7 bilhões entre imposto de renda e contribuição social por desconsideração de fusão realizada em

2008, levaram as ações da instituição bancária a uma queda de 2, 05\%. (Rodrigo Tolotti Umpieres. Efeito

Dólar: Fibria e CSN sobem mais de 7\%, enquanto empresas de consumo caem. Disponível em:

www.Infomoney.com.br/mercado/ações, Acessado em: 15/12/13).
} 
Portanto, a complexidade, a excessiva quantidade de obrigações acessórias e a ausência de uma graduação ou limite do poder sancionador estatal são fatores decisivos que impactam não apenas na concorrência, mas naatração de novos investimentos locais que, hoje, no mundo globalizado deixou de estar vinculado à noção de localização.

Estes pontos merecem uma maior reflexão por parte do Estado, pois sem que o contribuinte consiga perceber a importância do ICMS e, consequentemente, a melhoria que sua arrecadação proporciona para o desenvolvimento da sociedade e ao crescimento de sua atividade econômica, a tendência é adotar medidas para se evadir de sua tributação.

\section{A AUSÊNCIA DE DOSIMETRIA NAS MULTAS FISCAIS DO ICMS E SEU REFLEXO NO DESENVOLVIMENTO}

Ocorre que, se por um lado o Estado, a fim de combater a desigualdade social, visando a construção de uma sociedade livre, justa e solidária, passa a necessitar de recursos para oferecer bens e serviços à população, e com isso, amenizar a carência de seu povo, muitas vezes acaba por elevar a carga tributária, por não dispor de receitas suficientes para as atribuições que a constituição lhe impõe.

O fato é que o Estado, procedendo desta forma, interfere na economia, onerando produtos e serviços ou, até mesmo, levando à redução as margens de lucro de atividades econômicas, gerando, ao setor produtivo, dificuldades para o recolhimento do tributo.

Com receitas menores, a atividade econômica não consegue recolher o tributo em dia, acarretando sanções que, se não devidamente graduada, decretam o encerramento da atividade comercial.

O processo então vira cíclico e, acreditando que impor uma penalidade maior inibe o descumprimento, o Estado passa a esquecer alguns direitos, prejudicando a sua própria arrecadação.

Essa realidade de escassez de recursos acaba levando o Estado a enxergar no descumprimento de obrigações tributárias uma fonte de receita. Contudo, diferentemente do tributo que tem caráter eminentemente fiscal, a sanção não visa à arrecadação do Estado, mas sim, garantir o cumprimento do ordenamento jurídico. 
O fato é que as sanções sempre foram utilizadas como meio de controle social, pois, geralmente, visam garantir o cumprimento de determinada orientação normativa.

Neste sentido, soa por evidente que a utilização de uma penalidade pecuniária representa uma intervenção do Estado no Direito de liberdade do contribuinte, a partir do momento em que o Estado impõe uma grande quantidade de obrigações acessórias a cumprir, sem uma graduação na sanção devida pelo seu descumprimento, ou quando impõe elevadas multas pela falta de recolhimento do imposto, sem graduar seu impacto na atividade econômica.

É fácil observar que quando se subtrai do contribuinte os meios de pagamento e a liberdade de plena autonomia para conduzir sua atividade econômica, a liberdade e a propriedade são diretamente atingidas.

A livre iniciativa pressupõe o direito de gerir seu próprio negócio, por meio de uma atividade lícita, com liberdade na forma de constituição, sem que o Estado restrinja a possibilidade de o indivíduo participar do progresso social, e,assim, de viver dignamente.

O direito à livre iniciativa, embora não seja absoluto, possui um núcleo essencial que não pode ser restringido pelo ente público, mesmo em face de seu poder sancionador.

$\mathrm{O}$ fato é que tem sido frequente a imposição de multas fiscais pelo descumprimento de obrigação tributária principal ou acessória em percentuais bastante expressivos ${ }^{10}$, sem a observância de princípios constitucionais, como o da segurança jurídica, da proporcionalidade, da tipicidade fechada.

O fato é que assim como a tributação não deve ser implementada sem preservar a liberdade básica do indivíduo, o mínimo vital, o poder sancionador estatal também deve observar os princípios constitucionais, a fim de não impedir o funcionamento do mercado ou promover o confisco.

Um ambiente de insegurança, onde não se tenha proteção do direito de propriedade, repele investidores, ante o receio de prover capitais para financiar empreendimentos de terceiros.

\footnotetext{
${ }^{10}$ No quadro comparativo da multa fiscal por falta de recolhimento do imposto (obrigação principal) nos Estados do São Paulo, Pará, Ceará, Rio Grande do Sul e Mato Grosso, é possível observar que as penalidades chegam, respectivamente, a 300\%, $210 \%, 400 \%, 120 \%$ e $200 \%$ do valor do imposto. Já as multas pela falta de envio de informações econômico-fiscais (obrigação acessória) estabelecida pelo Estado do Pará, por exemplo, pode variar de 0,5\% do valor da saída, até o limite de 10.000 UPFPA, independentemente do recolhimento do imposto. (MERLIN; NOBRE, 2014, p. 347-348)
} 
Portanto, o Estado precisa entender que o ônus financeiro gerado pela sanção desproporcional de uma forma ou de outra o atingirá. Isto porque a tendência será o empresário repassar esse custo ao produto a ser consumido pela sociedade, dificultando a oportunidade de acesso da população a bens que estes possam considerarnecessários a uma vida boa. Ou, por outro lado, se o ônus for absorvido pelo segmento econômico, reduzirá seus investimentos, desestimulando o exercício da atividade laboral.

Em verdade, o gravame voltará para o próprio Estado, seja pelo agravamento da desigualdade na rendae maior sacrifício da população para a inserção social; seja na retração da arrecadação influenciada pela redução do consumo; seja pela ausência de investimentos traduzida, por exemplo, com a diminuição na contrataçãode funcionários ou com a desistência na implementação de novas tecnologias produtivas.

Neste sentido, é importante reconhecer que "As liberdades não são apenas os fins primordiais do desenvolvimento, mas também os meios principais" (SEN, 2000, p.25).

Assim, faz-se primordial verificar que a competência estatal, tanto para instituir o tributo como para efetivar o seu poder sancionador possui limites, dentro dos quais este não deve se afastar, sob pena de aniquilar o direito à livre iniciativa do contribuinte. É a proibição de excesso, como ensina Humberto Ávila (2012, p.158-159):

\footnotetext{
A aplicação da proibição de excesso não decorre da existência de uma relação de meio e fim. Ela decorre do dever de compatibilizar os direitos de liberdade com o interesse público na medida do possível. Essa tensão entre o indivíduo e a sociedade, isto é, a garantia de direitos fundamentais e a previsão de regras de competência devem ser harmonizadas.
}

Ademais, algumas multas aplicadas pelo descumprimento de uma obrigação acessória não guardam relação com a infração cometida e, em muitos casos, mesmo o contribuinte já tendo recolhido o imposto da operação, o simples inadimplemento de uma obrigação acessória, acarreta a imposição de uma multa pecuniária muito superior ao próprio valor do ICMS devido na operação.

Desta forma, é possível verificar que muitas multas tributárias, aplicadas pelo descumprimento de uma obrigação acessória, mesmo possuindo caráter instrumental, são graduadas pelo faturamento da empresa, sem que consiga observar critérios que justifiquem esta imposição. 
Assim, Hugo de Brito Machado (2004, p. 189) lembra que "não é o exagero da sanção, mas a efetividade desta, que desestimula as práticas ilícitas". ${ }^{11}$

Em outras palavras, não será a simples previsão normativa da multa fiscal que irá fazer com que o contribuinte observe a obrigação tributária, mas sim a sua efetiva aplicação, uma vez que o indivíduo, como ser racional, sempre irá avaliar os custos e benefícios antes de tomar a decisão.

O fato é que as sanções não devem ser tão pesadas ao ponto de inibir a própria atividade econômica. Não se pode esquecer a função social que a atividade carrega.

Neste sentido, Misabel Derzi (2006, p.337) sustenta:

Se a empresa cumpre uma função social e é geradora de empregos e riqueza, então a preservação não interessa apenas a seus credores, e aos investidores, mas ainda ao fisco, que se alimenta de sua capacidade econômica, e aos trabalhadores em geral.

Desta forma, uma sanção proporcional e adequada com o ilícito praticado não é apenas dever do ente público, mas passa a ser um direito subjetivo do contribuinte e da sociedade ao desenvolvimento.

Ademais, não podemos esquecer que outro fator gerado pela ausência de dosimetria na multa fiscal do ICMS que impacta no desenvolvimento é o custo administrativo e judicial.

Isso porque, quando sanções fiscais são imputadas e transformadas em créditos tributários, despidos de critérios claros e adequadamente ponderados, tais créditos geram autuações que, muitas vezes, tomam corpo sob a forma de litígios e acabam por abarrotar nossos Tribunais, seja na Instância Administrativa Tributária, seja no Judiciário.

Essas ações acarretam custos em função da máquina pública deslocada, por meio do grande número de atores envolvidos, dentre estes: auditores, procuradores de Estado, membros do Judiciário e, em algumas situações, do próprio Ministério Público do Estado onerando, assim, os cofres públicos.

Não obstante esses custos, muitas vezes esses créditos são reduzidos pela sua desproporcionalidade.

\footnotetext{
11 Michel Foucault, no século XX já comentava acerca da eficácia das punições: "sua eficácia é atribuída à sua fatalidade, não à sua intensidade visível; a certeza de ser punido é que deve desviar o homem do crime (...)” (FOUCAULT, 2013, p.14).
} 
A importância desta reflexão se deve em função de que, recentemente, no RE 754554 GO, o Ministro Marco Aurélio do Supremo Tribunal Federal,em decisão monocrática declarou ser inconstitucional a multa de $25 \%$ cobrada pelo Estado de Goiás em empresas que falsificam ou prestam informações erradas em notas fiscais do Imposto sobre a Circulação de Mercadorias e Serviços (ICMS). Em sua decisão, o Ministro afirmou:

Os entes estatais não podem utilizar a extraordinária prerrogativa de que dispõem em matéria tributária para exigirem prestações pecuniárias de valor excessivo que comprometam, ou, até mesmo, aniquilem o patrimônio dos contribuintes. ${ }^{12}$

O problema toma maiores preocupações, pois, se antes o Poder Judiciário apenas declarava a inconstitucionalidade da lei, com o tempo o Supremo Tribunal Federal tem reduzido e fixado percentuais que considera adequado, a depender do caso concreto $^{13}$. Ademais, este entendimento tem sido acompanhado em diversos Tribunais.

Portanto, a ausência de uma dosimetria nas multas fiscais impacta na liberdade da atividade econômica, gera ineficácia nos meios de repressão, fragilizando o Estado de Direito e conduzindo demandas ao judiciário, que em muitos casos já tem se pronunciado pela redução nos percentuais de multas lançadas nos autos de infração, propiciando, assim, que a competência legislativa tributária saia das mãos do legislador.

Neste sentido, é fundamental a eliminação de quaisquer barreiras que possam dificultar o direito de participação, de realização das liberdades básicas. Para isso, faz-se necessário além de políticas públicas eficazes, um ambiente econômico equilibrado para a promoção deste desenvolvimento.

O direito ao desenvolvimento, hoje compreendido como um direito fundamental, perpassa, sem dúvida alguma, pelo dever de solidariedade e a tributação é um de seus grandes exemplos.

\footnotetext{
${ }^{12}$ Neste julgamento, o STF demonstra entender, também, ser desproporcional a multa tributária que provoque restrição à livre iniciativa, ainda que não inviabilize inteiramente a atividade econômica.

13 No acórdão proferido pelo STF nos autos do Recurso Extraordinário no . 591969/ MG, cujo relator, Ministro Joaquim Barbosa,mencionando outras decisões da Corte, considera desproporcional multa igual ou superior a $100 \%$, reduzindo-a para $50 \%$.
} 


\section{CONCLUSÃO}

Se o tributo é a principal fonte de receita que dispõe o Estado para a garantia dos direitos fundamentais, faz-se necessário a compatibilização do sistema tributário com os demais princípios esculpidos no texto constitucional. Significa dizer que a concepção de tributação deixa de ser meramente formal para assumir um viés substancial.

É dentro desta moldura que o Estado, compreendendo a importância do seu papel como força motriz da sociedade, é fundamental para garantir o direito de propriedade, a estabilidade das relações sociais e o desenvolvimento da atividade econômica na sociedade capitalista moderna.

O ICMS é o imposto de maior arrecadação em nível nacional e tem uma importante função para o Estado na efetivação dos direitos fundamentais. Contudo, há muitos problemas na estrutura normativa do ICMS que impactam o desempenho da atividade econômica.

Ocorre que se a atividade econômica não consegue enxergar a importância da arrecadação do ICMS para a sociedade e se, o Governo do Estado não simplificar, desonerar e dosar o seu poder sancionador, o diálogo necessário à constituição de uma sociedade livre, justa e solidária não há como prosperar.

O descumprimento de uma obrigação tributária necessita ser sancionada pelo Estado, até mesmo para fomentar o recolhimento do tributo e garantir o respeito ao princípio da igualdade e da legalidade. No entanto, na graduação das multas tributárias, o Estado não pode esquecer o caráter instrumental para o qual a sanção foi estabelecida. $\mathrm{O}$ poder punitivo estatal não pode ser desproporcional com o ilícito praticado.

Assim, se por um lado as multas impostas pela Administração Pública têm como função punitiva, preventiva, indenizatória, pedagógica ou assecuratória do recolhimento do crédito tributário, a falta de uma dosimetria proporcional com a gravidade da infração e com a capacidade contributiva do contribuinte cria dificuldades para absorção deste impacto financeiro, inibindo o desenvolvimento, passando a esvaziar os objetivos esculpidos no texto constitucional.

Portanto, se as sanções são aplicadas dentro um contexto normativo, estas devem estar relacionadas com o direito a que se visa proteger. 
O desestímulo à prática de atos evasivos não deve, contudo, servir de fonte arrecadatória concorrente ou substitutiva da arrecadação do próprio imposto.

É verdade que o contribuinte ao praticar conduta contrária à disposição legal, sabe e se responsabiliza pelas conseqüências advindas de seus atos. Contudo, não retira do Estado a necessidade de balizar as multas levando em consideração não apenas o montante do imposto suprimido, mas, também, a gravidade da infração, a função da pena e a capacidade contributiva do contribuinte, uma vez que a sanção não deve ser tão gravosa ao ponto de desestimular, dificultar a atividade econômica, sob pena romper com os fundamentos do texto constitucional.

Desta forma, a ausência de uma dosimetria nas multas fiscais do ICMS provoca uma onerosidade econômica ao Estado em face dos custos estatais envolvidos, a judicialização da competência legislativa tributária, desestimula investimentos e onera o setor produtivo, prejudicando a competitividade das empresas, vindo a inibir o desenvolvimento econômico e social do país.

\section{REFERÊNCIAS}

ÁVILA, Humberto. Sistema Constitucional Tributário. 5 ed. São Paulo: Saraiva, 2012.

BARQUERO ESTEVAN, J. M., La funcióndel tributo em el Estado social y democrático de derecho, Madrid, Centro de estúdios políticos y constitucionales, 2002.

BARCELLOS, A. P., A eficácia jurídica dos princípios constitucionais: o princípio da dignidade da pessoa humana, Rio de Janeiro, Renovar, 2002.

BIDART CAMPOS, G. J., El orden socioeconómico em la Constitución, Buenos Aires, Editar, 1999.

BRASIL. Constituição (1988). Constituição da República Federativa do Brasil: promulgada em 5 de outubro. 14. Ed. Vade Mecum. São Paulo: Saraiva. 2012.

BRASIL, STF . RE 754554 GO, Rel. Min. Celso de Mello, 20/10/2013. $2^{\text {a }}$ Turma. ACÓRDÃO ELETRÔNICO DJe-234 DIVULG 27-11-2013 PUBLIC 28-11-2013.

BRASIL, STF. RE 591969 MG, Rel. Min. Joaquim Barbosa, DJe - 05/03/2009.

BERCOVICI, Gilberto. In SCHAPIRO, Mário Gomes. Novos Parâmetros para Intervenção do Estado na Economia. São Paulo: Saraiva, 2010. 
CARDOSO, Alessandro Mendes. O dever fundamental de recolher tributos no Estado democrático de direito. Porto Alegre: Livraria do Advogado Editora, 2014.

DERZI, Misabel Abreu. O Princípio da Preservação das Empresas e o Direito à Economia de Imposto. In ROCHA, Valdir de Oliveira. (Org.). Grandes Questões atuais do Direito Tributário. São Paulo: Dialética, 2006, v. 10.

DELGADO, J. A., "A interpretação contemporânea do direito tributário e os princípios da valorização da dignidade da pessoa humana e da cidadania”, In: FISCHER, O. C (org.), Tributos e Direitos Fundamentais: São Paulo, Dialética, 2004, p.151-216.

ESCRIBANO, F., La configuración jurídica del deber de contribuir: perfiles constitucionales, Madrid, Civitas, 1998.

FERRAZ, R., "A inconstitucionalidade dinâmica da Cide-combustíveis", In: ROCHA, V. O. (org.), Grandes questões atuais do direito tributário, v. vol. 9, São Paulo, Dialética, 2005, p.423-462.

FOUCAULT, Michel. Vigiar e punir. 19 ed., Petrópolis: Ed. Vozes, 1999.

INSTITUTO BRASILEIRO DE PLANEJAMENTO TRIBUTÁRIO - IBPT. Carga Tributária Brasileira 2012. disponível em: www.ibpt.com.br, Acessado em: 10.12.2013.

MACHADO, Hugo de Brito. Teoria das Sanções Tributárias. In Sanções Administrativas Tributárias. Coordenador Hugo de Brito Machado. 2004. . Curso de Direito Tributário. 28 ed. São Paulo: Malheiros, 2007.

NOBRE, Simone; MERLIN, Lise. Elementos para a (Re)fundação das multas fiscais. In:

MURTA, Antônio Carlos Diniz; BALTHAZAR, Ubaldo César; FEITOSA, Raymundo Juliano Rêgo (coord.). Direito Tributário [recurso eletrônico on-line]. Florianópolis:CONPEDI, $2014 . \quad$ P. 341-360. Disponível em:

http://www.publicadireito.com.br/publicacao/ufsc/livro.php?gt=71.

RECEITA FEDERAL. Carga Tributária no Brasil 2010 - análise por tributos e bases de incidência, 2011.

Rodrigo Tolotti Umpieres. Efeito Dólar: Fibria e CSN sobem mais de 7\%, enquanto empresas de consumo caem. Disponível em: www.Infomoney.com.br/mercado/ações, Acessado em: 15/12/13

SEN, Amartya. Desenvolvimento como liberdade.Trad. Laura Teixeira Motta; São Paulo: Companhia das Letras, 2000. 
TORRES, Ricardo Lobo."Valores e princípios no direito tributário ambiental", In: TORRES, H. T (org.), Direito tributário ambiental, São Paulo: Malheiros, 2005-A, p. 21 54.

.Tratado de Direito constitucional Financeiro e Tributário - osdireitoshumanos e a tributação: imunidade e isonomia. 3. ed. Rio de Janeiro: Renovar, 2005-B.

TRIBEL, M., "Derechos humanos como limite a la potestade tributária", Revista de Direito Tributário, V. 14, n. 52, 1990.

STEICHEN, A., "La justice fiscale entre la justice commutative et la justice distributive", Archives de Philosophie du Droit, n. 46, 2002, p.243-279. 